\title{
Midwifery e obstetrícia: uma variação denominativa
}

\author{
Midwifery and obstetrícia: a denominative variation
}

\author{
Yuli Souza Carvalho*
}

\begin{abstract}
RESUMO: A área de obstetrícia possui tradições muito vinculadas à cultura de cada país. Tendo em vista esse contexto, o presente trabalho tem o objetivo de tratar da variação denominativa existente no par de línguas inglês e português em um artigo acadêmico desse âmbito. Com base no texto Counting Time in Pregnancy and Labour (DOWNE; DYKES, 2009) e na tradução feita pela autora do artigo, trataremos das traduções de termos técnicos, principalmente vinculados à área de atuação das midwives, que ilustram essas diferenças culturais na forma em que o parto ocorre na Inglaterra e no Brasil. Como resultado, foi possível observar que a escolha de traduzir 'midwifery' por 'obstetrícia', apesar de ter sido aconselhada por uma profissional da área, não foi a solução considerada mais adequada. Foi possível concluir que, em um contexto em que há discrepância entre as culturas do país-fonte e do país-alvo, seria conveniente que o tradutor escrevesse um prefácio ou nota do tradutor onde fosse explicado de que forma ocorrem essas diferenças culturais.
\end{abstract}

PALAVRAS-CHAVE: terminologia; variação denominativa; tradução técnica; obstetrícia.

ABSTRACT: Obstetrics is a branch of Medicine with traditions ingrained in the culture of each country. In this context, the objective of this article is to study in which means is possible to observe denominative variation in English and Portuguese in an academic text of this area. Using as basis the text Counting Time in Pregnancy and Labour (DOWNE; DYKES, 2009), and its translation made by the article's author, we will discuss the translation of technical terms that can illustrate these cultural differences in the ways which childbirth is performed in England and Brazil. As a result, it was possible to notice that the translate choice 'midwifery' as 'obstetrícia', even though recommended by a professional of the field, was not the most adequate solution. It was possible to conclude that in this context, whereby the cultures surrounding translation are greatly different, it

would be convenient if the translator could write a preface or translator's note, explaining in which way these cultural differences occur.

KEYWORDS: terminology; denominative variation; technical translation; midwifery.

\footnotetext{
* Mestranda em Estudos da Linguagem pela Universidade Federal do Rio Grande do Sul. Bacharela em Letras (Português/Inglês) pela Universidade do Rio Grande do Sul. E-mail: yuli@live.ca.
} 


\section{Introdução}

A obstetrícia é uma área de atuação que possui tradições muito vinculadas à cultura de cada país. $\mathrm{O}$ tipo de abordagem adotada na hora de lidar com o parto, bem como a hierarquia no que tange à estrutura médica são exemplos que poderemos observar no capítulo produzido em inglês britânico e na sua tradução para o português brasileiro, que são o centro da análise no presente trabalho. Por se tratarem de culturas tão distintas em relação ao âmbito médico, o texto, escrito originalmente em um cenário de produção britânico, criou algumas dificuldades no processo tradutório para a língua portuguesa - principalmente no que se refere à terminologia.

Dessa forma, sob a luz da Teoria Sociocognitiva da Terminologia de Rita Temmerman (2004), o objetivo deste trabalho é descrever se há variação denominativa proveniente de perspectivas culturais diferentes entre "país-fonte" e "país-alvo"8, no cenário de produção do capítulo Counting Time in Pregnancy and Labour $^{9}$ (DOWNE; DYKES, 2009) e no cenário de tradução desse texto.

\section{A obra e o processo de tradução}

O capítulo Counting Time in Pregnancy and Labour - bem como o restante do livro de que faz parte - se situa na área de obstetrícia, sendo abordada tanto a perspectiva da área médica quanto a perspectiva da área da Enfermagem. A variação de que trataremos posteriormente foi percebida durante o processo de tradução do texto mencionado anteriormente, escrito pelas autoras Soo Downe e Fiona Dykes (2009) e publicado em um livro intitulado Childbirth, Midwifery and Concepts of Time - sua capa pode ser observada na Figura 1.

\footnotetext{
${ }^{8}$ A utilização das expressões "país-fonte" e "país-alvo" ocorre como relação ao que se utiliza de forma difundida para falar de originais e traduções como "texto-fonte" e "texto-alvo".

$9 \mathrm{Na}$ tradução final, o capítulo ficou intitulado Contando o tempo na gravidez e no parto.
} 
Figura 1 - Capa do livro Childbirth, Midwifery and Concepts of Time

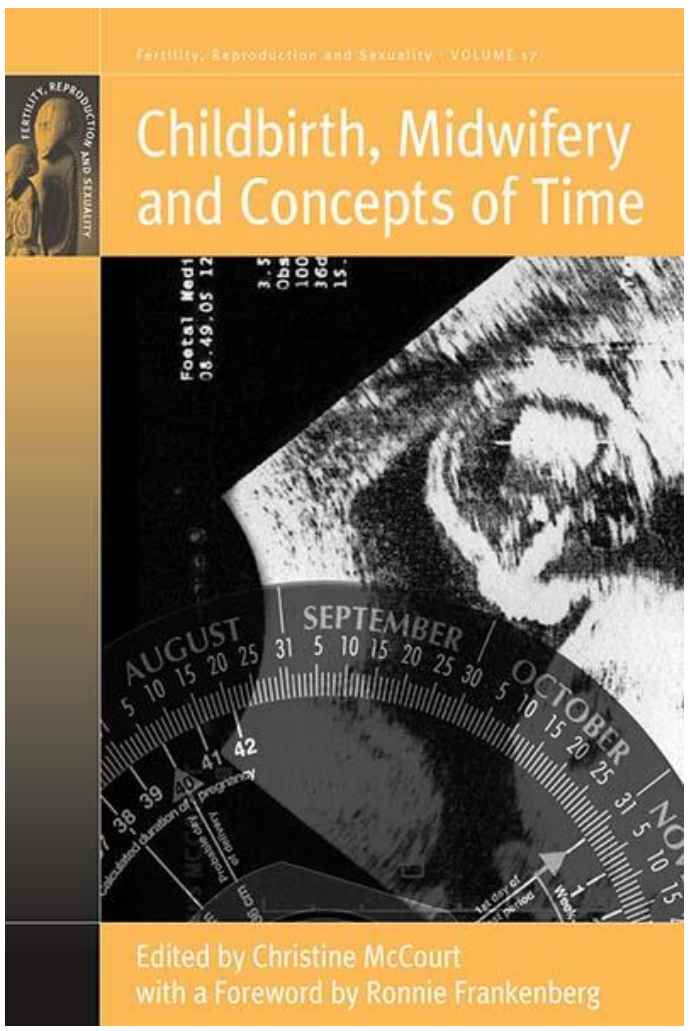

Fonte: Berghahn Books (2020).

A tradução do livro (na íntegra) de McCourt (2009) foi solicitada pessoalmente por uma professora da área de Enfermagem, partindo da premissa de que há uma falta de produção de textos nessa temática em língua portuguesa. Assim, como o produto final da disciplina da graduação 'Estágio Supervisionado de Tradução II', cada aluno ficou responsável pela tradução de um capítulo, que posteriormente passaria por uma revisão a fim de padronizar os textos. A tradução do capítulo em questão foi desenvolvida pela autora deste artigo, sob a orientação da professora Márcia Moura da Silva, que ministrou a disciplina no semestre de 2017/2. Inclusive, posteriormente, esse trabalho de tradução foi também foco de análise do trabalho de conclusão de curso da autora (CARVALHO, 2018). Até o momento, não há previsão de publicação do livro.

Por ter sido solicitada pessoalmente por uma professora de Enfermagem, foi possível manter um diálogo com uma especialista, que acabou auxiliando na escolha de termos que seriam mais apropriados e mais utilizados no contexto 
dessa área de especialidade no cenário brasileiro. De acordo com Temmerman (2004, p. 45), “o especialista [...] será necessário para consultoria ad hoc em caso de dificuldades na identificação da terminologia ao longo da análise dos textos”. No cenário da nossa tradução, essa consultoria se deu no movimento de tradução, na hora de escolher os termos que seriam utilizados como equivalentes àqueles contidos no original, por acreditarmos que a terminologia utilizada no texto deveria ser aquela mais convencional aos olhos dos especialistas. Também, nesse sentido, Krieger e Finatto (2004, p. 125) afirmam ser "importante contar com o diálogo e com a cooperação dos especialistas de uma área de conhecimento para que possamos, como profissionais da língua, nos movimentar razoavelmente por seus textos e por sua linguagem".

Vale ressaltar também que, a fim de manter as escolhas terminológicas coerentes em todo o livro, foi feito um glossário colaborativo numa planilha no Google Sheets. Dessa maneira, todos os alunos que estavam trabalhando na tradução de capítulos do livro poderiam fazer suas contribuições. Nesse glossário, poderíamos compartilhar os termos presentes no capítulo que estávamos traduzindo em língua inglesa, seguido de sua(s) respectiva(s) escolha(s) tradutória(s) para a língua portuguesa.

O capítulo Counting Time in Pregnancy and Labour (DOWNE; DYKES, 2009), que está no centro desta análise, trata das relações existentes entre tempo e progresso na gravidez, além de analisar como o tempo é monitorado e medido, tanto na gravidez quanto no parto. As autoras do texto abordam esses aspectos no âmbito do parto natural nas perspectivas feminista, consumista, socioeconômica e da teoria da complexidade. Antes de entrar na análise dos termos e dos contextos de circulação do texto original e do texto traduzido (Seção 4), será feita uma introdução à teoria de Terminologia proposta por Rita Temmerman (2004), que guiará as reflexões do presente trabalho. 


\section{Teoria Sociocognitiva da Terminologia}

A Teoria Sociocognitiva da Terminologia foi proposta por Rita Temmerman (2004) em meados dos anos 1990. Baseando-se em um levantamento das terminologias das ciências biológicas, seu estudo surgiu como uma proposta de nova Teoria Geral da Terminologia, posicionando-se como uma "reação" à teoria anteriormente elaborada por Wüster. Temmerman (2004) se refere a esta teoria de Wüster como "Teoria Tradicional da Terminologia", por acreditar que não se trata de uma teoria geral, o que ele propunha que fosse.

A Teoria Geral da Terminologia de Wüster tem como um dos objetivos promover uma padronização das terminologias. Ou seja, ela se coloca como busca de uma terminologia única e universal, a fim de facilitar a comunicação dos especialistas. Dessa forma, a teoria tradicional teria uma perspectiva monossêmica do termo, em que cada conceito equivaleria a um termo, em uma relação de um para um. Uma grande crítica a esse movimento unívoco de conceito para termo é de que esse seria um tipo de tratamento prescritivo da terminologia. Além disso, se trataria de uma perspectiva in vitro da língua, pois estaria partindo de uma visão da língua como ideal normatizado, desconsiderando os contextos e diversos aspectos, como as diferentes culturas, visões de mundo, evolução das línguas etc.

Por isso, ao se posicionar contra a teoria tradicional, Temmerman (2004) formula cinco princípios alternativos para a criação de uma nova teoria geral da terminologia. O primeiro princípio é que a Teoria Sociocognitiva partiria de unidades de interpretação que possuem estrutura prototípica. Ou seja, por acreditar que poucos conceitos existem no mundo como objetos, ela afirma que as pessoas entendem o mundo por meio de sistemas cognitivos ou modelos que se relacionam com essas unidades de interpretação. Assim, essa teoria se coloca numa abordagem semasiológica, tendo o termo como o ponto de partida - e não o conceito, como era o proposto por Wüster. Para tal, a autora acredita que os 
termos precisam ser estudados dentro do discurso das áreas em foco, partindo então para uma perspectiva in vivo da língua.

O segundo princípio é uma afirmação de que a compreensão é um evento estruturado. Ou seja, a um conceito é necessário que se atribua uma posição numa estrutura conceitual. Pode ser um tipo de classificação lógica, como por exemplo “ $x$ é um tipo de $y$ ”, ou uma classificação ontológica, como por exemplo “ $x$ é parte de $y$ ".

O terceiro princípio afirma que o modelo de compreensão pode ser formado por módulos diferentes de informação. De acordo com Temmerman (2004, p. 38), esses “módulos de informação podem conter informações mais ou menos essenciais, dependendo do tipo de unidade de interpretação e de outros fatores tais como a perspectiva a partir da qual a unidade é entendida”. Para ilustrar esse princípio ela traz o exemplo do termo 'biotecnologia', que seria definido de formas diferentes na área da medicina ou da indústria de alimentos, pois os módulos de informação que comporiam a definição conteriam graus diferentes de importância.

O quarto princípio, que se coloca contra a visão monossêmica do termo da teoria tradicional, postula que a sinonímia e a polissemia existem e são funcionais no desenvolvimento da compreensão. Não se pode ignorar a existência desses fenômenos. A autora apresenta, ainda, a ideia de que há três razões simultâneas para a polissemia:

\footnotetext{
A primeira delas é a transformação no mundo em decorrência de uma nova tecnologia ou transformação social. Uma segunda razão pode residir no nível cognitivo: uma transformação no entendimento da categoria. Uma terceira razão reside nas possibilidades e limitações oriundas da totalidade dos elementos de transformação inerentes à linguagem enquanto sistema. (TEMMERMAN, 2004, p. 40).
}

Ou seja, a polissemia é um elemento que é inerente às línguas naturais. Dessa forma, é importante levá-la em consideração na hora de fazer um estudo in vivo da língua.

O quinto princípio traz uma perspectiva diacrônica, que será de grande relevância para a análise proposta por esse trabalho. A autora traz a ideia de que 
as unidades de interpretação estão em constante evolução, como um resultado da busca por um entendimento maior e mais amplo, da interação que ocorre entre os diferentes usuários das línguas e como uma consequência da estrutura prototípica na compreensão de categorias.

A partir desses cinco princípios, ela postula três métodos de análise terminológica, que se distanciam daquilo que era o paradigma teórico tradicional wüsteriano. Os métodos de análise listados pela autora são: 1) análise da estrutura prototípica, que examina as relações que ocorrem dentro de uma categoria; 2) análise de modelo cognitivo, que trata das relações intercategoriais, ou seja, aquelas que uma categoria pode apresentar com outras categorias da mesma área de experiência; e 3) análise diacrônica, que considera a história das categorias, mostrando que o ato de nomear raramente é algo arbitrário e é um processo que se dá no tempo.

Com base no referencial teórico aqui apresentado, a próxima seção apresentará um estudo sobre a variação denominativa entre o original e a tradução do texto Counting Time in Pregnancy and Labour (DOWNE; DYKES, 2009).

\section{Contextualização e análise}

A questão da variação denominativa de que trataremos nessa análise surgiu durante o processo de tradução do capítulo Counting Time in Pregnancy and Labour (DOWNE; DYKES, 2009), como mencionado anteriormente. Neste momento, vale ressaltar o que se entende por variação denominativa. $O$ fenômeno da variação denominativa ocorre quando um determinado conceito de uma dada área do conhecimento humano (técnico, científico, cultural etc.) é denominado por dois (ou mais) diferentes termos. Em outras palavras, quando há diferentes unidades terminológicas em uma língua natural (neste caso, duas línguas naturais) que são usadas em contextos de comunicação especializada para denominar um mesmo conceito. Há também o movimento contrário, quando 
uma única unidade léxica é usada para denominar diferentes conceitos em uma mesma área do conhecimento, tratando-se, então, de um caso de variação conceitual (PEREIRA; NADIN, 2019).

O fenômeno da variação denominativa, no geral, leva em consideração apenas o contexto linguístico de uma língua. Entretanto, apesar de estarmos levando em consideração duas línguas e culturas diferentes (o inglês britânico e o português brasileiro), para os fins deste trabalho, acreditamos que esse fenômeno possa aplicar-se ao contexto da tradução. Para explicar de que forma ocorre a variação, serão apresentados os contextos da Inglaterra e do Brasil no que diz respeito à prática de obstetrícia.

O texto, escrito no cenário de produção da Inglaterra, trata de uma perspectiva natural e humanizadora do parto. Acreditamos, justamente em decorrência desse cenário, tão diferente do que atualmente observamos no Brasil, que foi solicitado por uma professora do curso de Enfermagem que fosse executada a tradução integral do livro Childbirth, Midwifery and Concepts of Time.

O livro, publicado no ano de 2009, possui onze capítulos e está dividido em três partes. A primeira parte trata do contexto histórico e cultural da obstetrícia. A segunda parte trata do tempo e das práticas de parto. Por fim, a terceira parte trata do tempo e das experiências de parto. Cada capítulo foi escrito por diferentes autores, portanto optou-se por cada um dos capítulos também ser traduzido por diferentes tradutores - que eram alunos da disciplina de 'Estágio Supervisionado de Tradução do Inglês', como mencionado anteriormente.

Como apresentado na segunda seção, durante o processo de tradução, montamos um glossário de termos, onde acrescentávamos os termos em inglês que apareciam no texto em que estávamos trabalhando, seguido do(s) equivalente(s) que utilizamos na tradução para o português. Ainda, posteriormente, o texto passaria por uma revisão para uma padronização na terminologia, a fim de ser publicado. O texto que serve de objeto da análise proposta nesse trabalho é parte do capítulo de número três do livro, situado na segunda parte, que trata do tempo e das práticas do parto. 
'Midwifery', um dos termos que apresenta o que tratamos aqui como variação denominativa, é definido como "profissional responsável e confiável, que trabalha em parceria com as mulheres, fornecendo apoio, cuidados e conselhos durante a gravidez, o parto e o pós-parto, realiza partos e presta cuidados ao recém-nascido" (INTERNATIONAL CONFEDERATION OF MIDWIVES, 2017, on-line, tradução minha) ${ }^{10}$. O termo já ocorre no título do livro, e é apresentado diversas vezes no decorrer dos capítulos. Na introdução dos conceitos e das filosofias do capítulo Counting Time in Pregnancy and Labour, as autoras Downe e Dykes escrevem (seguido do trecho traduzido pela autora do artigo):

Indeed, one of us (SD) came to midwifery with the belief that childbirth can be a site of feminist praxis, or change, and that such change could make a profound difference to individual women and to society. (DOWNE; DYKES, 2009, p. 62, grifo meu).

De fato, uma de nós (Soo Downe) se voltou à obstetrícia com a crença de que o parto pode ser um centro de práticas feministas, ou mudanças, e que tais mudanças poderiam fazer uma diferença significativa para mulheres individualmente e para a sociedade. (DOWNE; DYKES, 2009, p. 62, tradução minha, grifo meu).

Dessa forma, enxergamos aqui a variação denominativa como a diferença na denominação da área de atuação que envolve o parto, chamada de 'midwifery' na Inglaterra e traduzida para 'obstetrícia' na tradução. Essa variação ocorre devido às diferenças culturais na estruturação e na forma de atuação dessa área nos contextos de criação (país-fonte) e de tradução do texto (país-alvo). De acordo com Acker et al. (2006), fenômenos como esse sofrem influências do meio, principalmente em relação ao ritual do nascimento:

O nascimento é um evento carregado de significados e tratado comportamentalmente diferente nas diversas sociedades. Estas sociedades, representadas por diferentes grupos étnicos, raciais, religiosos e mesmo classes sociais, marcadas por múltiplas e diferentes culturas, possuem uma diversidade de orientações em relação à saúde,

\footnotetext{
${ }^{10}$ No original: "as a responsible and accountable professional who works in partnership with women to give the necessary support, care and advice during pregnancy, labour and the postpartum period, to conduct births on the midwife's own responsibility and to provide care for the newborn and the infant."
} 
bem como em relação a métodos e práticas relacionados ao ciclo gravídico-puerperal. Vários autores se referem a eles como rituais. (ACKER et al., 2006, p. 648).

Para entender de que forma a tradução se aproxima ou se distancia do original por causa da variação denominativa citada, é importante apresentar uma contextualização diacrônica do domínio a ser analisado. Portanto, como sugerido por Temmerman (2004), serão contextualizadas as áreas que dizem respeito ao parto no cenário da Inglaterra e do Brasil.

\subsection{A relação com o parto no Brasil}

O contexto do parto no Brasil, atualmente, tem uma perspectiva totalmente mercadológica. De acordo com Odoshina (2017, p. 67), "O parto é abordado como um produto comercializável, sujeito às regras de mercado". Assim, os médicos veem o parto puramente como uma mercadoria, que deve render lucros e para isso deve ser feita o mais rápido possível para que seja mais rentável para eles.

Por causa dessa perspectiva, o Ministério da Saúde (BRASIL, 2017) registrou que, entre os anos 2000 e 2015, os índices de partos por cesárea aumentaram de $40 \%$ para $57 \%$ (Figura 2). Esse aumento é muito significativo e demonstra o quanto os médicos vêm fazendo essas intervenções que são desnecessárias e só servem para tornar o procedimento mais rápido para que eles atendam cada vez mais mulheres no menor tempo possível. 
Figura 2 - Índice de cesarianas no Brasil

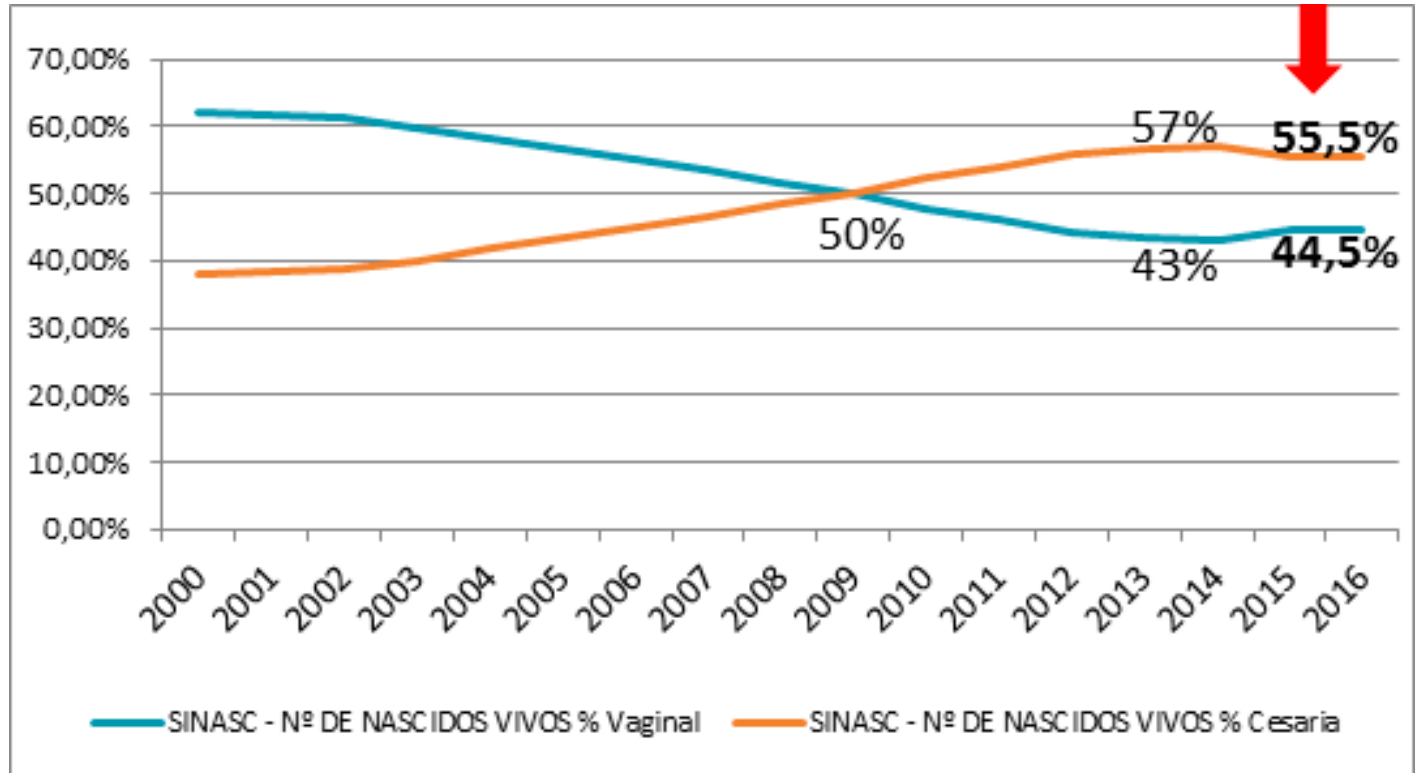

Fonte: Ministério da Saúde (BRASIL, 2017).

Além disso, de acordo com Guedes (2018), o Brasil ocupa o segundo lugar mundial em número de cesarianas. Enquanto o recomendado pela Organização Mundial da Saúde é que até $15 \%$ dos partos sejam feitos por cesárea, a realidade é que o Brasil, com $57 \%$ de partos por cesárea, só fica atrás da República Dominicana, lugar em que mais de $58 \%$ dos partos feitos são cesarianas. Em relação a esse índice, uma médica obstetra afirma que grande parte das cesarianas que estão sendo performadas no Brasil é feita de forma opcional, sem envolver fatores de risco que justifiquem a cirurgia. Também, elas são feitas antes de a mulher entrar em trabalho de parto. Há muitos locais em que faltam as condições necessárias de assistência, que favoreçam o sucesso do parto vaginal, tanto no setor público como no privado (GUEDES, 2018).

De acordo com o Ministério da Saúde (BRASIL, 2017, on-line), a organização pretende reduzir essas altas taxas de intervenções desnecessárias "como [...] a cesariana [...]. Tais intervenções, que deveriam ser utilizadas de forma parcimoniosa, apenas em situações de necessidade, são muito comuns, o que deixou de considerar os aspectos emocionais, humanos e culturais envolvidos no processo". Acreditamos que isso deve ter tido um reflexo no processo do parto 
nos últimos anos, como pode ser observado na Figura 2, com o não-aumento das taxas de cesáreas que ocorreu no ano de 2016. Provavelmente também é esse o motivo pelo qual as professoras do curso de Enfermagem necessitam de mais material abordando o tema do parto natural e humanizado sendo disponibilizado para os alunos, a fim de que sejam formados profissionais já com essa perspectiva de não fazer uso de intervenções que não sejam estritamente necessárias.

Outro aspecto que está presente no cenário brasileiro atual de assistência à maternidade, além dessas intervenções desnecessárias influenciadas pelos médicos responsáveis, é o da violência institucional. Essa violência é entendida, de acordo com Aguiar, d'Oliveira e Schraiber (2013, p. 2288), como "a transformação de uma diferença em desigualdade numa relação hierárquica com o objetivo de explorar, dominar e oprimir o outro que é tomado como objeto de ação, tendo sua autonomia, subjetividade, comunicação e ação livres impedidas ou anuladas”. Ou seja, ela é mais um reflexo da forma com que os médicos lidam com as pacientes gestantes nos momentos que precedem e seguem o parto. Essa violência, em sua maioria presenciada em maternidades públicas, se dá em forma de maus-tratos, xingamentos, abusos de autoridade, e outras formas de desrespeito com as pacientes parturientes. De acordo com as autoras, esse tipo de violência muito se dá em razão da sobrecarga de demanda que os médicos possuem, aliada à precariedade de recursos materiais e humanos com as quais eles precisam lidar e ainda assim prestar os seus serviços.

Dessa forma, no que diz respeito à tradução do termo 'midwifery', o equivalente que seria prima-face para o termo não seria 'obstetrícia', mas sim 'parteria', fazendo referência ao trabalho feito por parteiras. O Ministério da Saúde define "como parteira tradicional aquela que presta assistência ao parto domiciliar baseada em saberes e práticas tradicionais e é reconhecida pela comunidade como parteira” (BRASIL, 2010, p. 11). Considerando as informações postas aqui nos últimos parágrafos, na obstetrícia atual não há muito espaço para que as parteiras desempenhem sua função na hora do parto.

Essa função atualmente é desempenhada pelo médico obstetra, em uma abordagem muito diferente daquela feita pelas parteiras. Acker et al. (2006) 
afirma que durante muito tempo a assistência à mulher em trabalho de parto foi feita pelas parteiras. Essas mulheres, que desempenhavam possivelmente a profissão mais antiga da história, trabalhavam sem receber remuneração, muitas vezes executando esse trabalho apenas com base em suas experiências passadas. As parteiras (ou também chamadas assistentes de parto) eram mulheres, muitas vezes amigas, vizinhas, mães, ou pessoas escolhidas na comunidade, que eram consideradas capacitadas para dar auxílio às gestantes na hora do parto. Segundo os autores, foi somente no século XVII que surgiram os primeiros homens desempenhando esse papel, que era estritamente vinculado às mulheres. Os homens que ajudavam no atendimento à gestante eram, muitas vezes, homens que trabalhavam auxiliando o parto de animais. Dessa forma, o parto era feito sempre sob a ordem dessas mulheres com a ajuda de alguns raros homens, mantendo essa tarefa longe dos médicos e cirurgiões, que só interfeririam quando houvesse casos mais graves (ACKER et al., 2006).

De acordo com Acker et al. (2006) foi a partir dos anos 1970 que as parteiras foram perdendo a força. Os médicos as culpavam de infecções que as parturientes acabavam contraindo, justificando que a culpa seria das parteiras em decorrência da falta de higiene e de assepsia. Dessa forma, a medicina começou a "tomar posse" desse ritual que é o parto. A partir desse movimento, é no final do século XIX que surgem, no Rio de Janeiro, as primeiras maternidades (ACKER et al., 2006). Em decorrência desse cenário, a obstetrícia praticada por médicos nos hospitais foi se desenvolvendo de forma a evoluir até chegar no cenário que observamos atualmente.

Vale ressaltar que, de acordo com Guedes (2018), a humanização do parto no Brasil é um assunto que tem sido debatido no Senado ao longo dos anos, principalmente devido aos altos índices de cesarianas realizadas no país. O tema não só vem sendo discutido como ele também já foi abordado em um dos filmes de uma trilogia cinematográfica, chamada O Renascimento do Parto (2013; $2018 ; 2018 b)$.

O primeiro filme da trilogia (O RENASCIMENTO..., 2013) apresenta conceitos essenciais, como, por exemplo, o de parto humanizado como sendo 
aquele em que as escolhas da mãe são respeitadas. Nesse filme documental, também é explicado o papel da doula, que se trata de uma acompanhante treinada, cuja presença ajuda antes, durante e depois do nascimento. De acordo com Barbosa et al. (2018), apesar de, em sua origem, o termo 'doula' significar uma "mulher que serve", no cenário atual se refere "à pessoa que dá suporte emocional à mulher intraparto, com treinamento específico sobre fisiologia do parto normal, métodos não farmacológicos para alívio da dor, cuidados pósnatais e aleitamento materno" (p. 421). O segundo filme da trilogia (O RENASCIMENTO..., 2018) trata da violência obstétrica - tema que foi abordado anteriormente nesta seção. Por fim, o último filme da trilogia (O RENASCIMENTO..., 2018b) também faz uma costura dos temas abordados no primeiro e no segundo filmes. Isso demonstra que está havendo uma abertura no cenário brasileiro ao parto natural e humanizado, o que pode trazer evoluções significativas no que diz respeito a essa abordagem.

Para traçar um paralelo com o cenário onde o texto foi originalmente escrito pelas autoras Soo Downe e Fiona Dykes, é necessário que seja mostrado como esse cenário se afasta do cenário brasileiro, que é para onde o texto está sendo traduzido.

\subsection{A relação com o parto na Inglaterra}

Como mostrado anteriormente na Figura 2, no Brasil, o índice de cesáreas já havia passado dos 50\% no ano de 2010. Já no cenário da Inglaterra, como pode ser observado na Figura 3, entre os anos de 2011 e 2014 os índices de cesárea atingiram 26,2\%. Isso é pouco mais da metade do número desse tipo de intervenção cirúrgica no nosso país. Entretanto, ainda assim, o número extrapola os 15\% indicados pela Organização Mundial da Saúde. 
Figura 3 - Números da maternidade na Inglaterra

$\begin{array}{lccc} & 2011-12 & 2012-13 & 2013-14 \\ \text { Caesarean Rate } & 25.0 \% & 25.5 \% & 26.2 \% \\ \text { Elective } & 10.2 \% & 10.7 \% & 13.2 \% \\ \text { Emergency } & 14.8 \% & 14.8 \% & 13.0 \% \\ \text { Instrumental Delivery Rate } & 12.9 \% & 12.8 \% & 12.9 \% \\ & & & \\ \text { Forceps } & 6.6 \% & 6.8 \% & \mathrm{n} / \mathrm{a} \\ & & & \\ \text { Ventouse } & 6.3 \% & 6.0 \% & \mathrm{n} / \mathrm{a} \\ & & & \\ \text { Induction Rate } & 22.1 \% & 23.3 \% & 25.0 \% \\ & \text { Fonte: National Childbirth Trust (2015). }\end{array}$

De acordo com Downe e Dykes (2009), essa indução, que é feita para que as pacientes escolham o parto de cesárea, muitas vezes vem dos próprios médicos. Ela é uma negligência com as parturientes, pois as fazem acreditar que passar por essa intervenção cirúrgica - que é, diversas vezes, desnecessária - seria a forma mais confortável de lidar com o cenário do parto. Podemos observar, com os índices da Figura 3, que essa indução parece ser bem menos frequente na Inglaterra do que no Brasil. Porém, apesar desses baixos índices, outras formas de controle sobre o parto são utilizadas, como reportado pelas autoras Downe e Dykes (2009) no capítulo que elas escreveram. Um exemplo disso é o uso de intervenção por meio de óleo de rícino, fazendo que o parto comece antes do que começaria se os responsáveis pelo parto aguardassem o tempo da parturiente (DOWNE; DYKES, 2009).

As midwives, no cenário da Inglaterra, possuem um status totalmente diferente. Enquanto no Brasil o conhecimento que as parteiras possuem é apenas 
por meio das experiências prévias, no Reino Unido ${ }^{11}$, de acordo com Bachman (2018), desde o início do século XIX essas profissionais precisam passar por uma capacitação supervisionada para serem então registradas como midwives e poderem fazer acompanhamento nos partos.

No cenário pós segunda guerra mundial, no Reino Unido, começou a haver uma maior preocupação com o sistema público de saúde. Eles pretendiam instaurar no país um sistema de saúde acessível para todos. Esse sistema possuiria uma nova perspectiva não somente em relação a hospitais, médicos e dentistas, mas também em relação a enfermeiras e midwives no âmbito privado e público, fazendo com que elas se tornassem "o coração de diversas comunidades" (BACHMAN, 2018, on-line, tradução minha) ${ }^{12}$. No que diz respeito ao cenário atual de assistência à maternidade, a autora escreve:

\begin{abstract}
Enquanto hoje a maioria dos partos no Reino Unido são feitos em hospitais em vez de em casa, midwives são profissionais em seus próprios direitos, cuidando das necessidades das mães e dos bebês ao longo da gravidez, do parto e do período pós-parto por cerca de um mês. Tanto em casa, como no hospital ou em uma midwife unit, elas estão conduzindo os profissionais de saúde e assistindo a maioria dos partos. (BACHMAN, 2018, on-line, tradução minha) ${ }^{13}$.
\end{abstract}

Dessa forma, podemos observar essa não equivalência entre os termos 'midwife' e 'parteira', tanto quanto como entre 'midwife' e 'obstetra'. Esse distanciamento entre as expressões pode ser ilustrado também em um trecho do texto de Downe e Dykes (2009):

The role to determine the end of labour rested firmly with a senior doctor: 'The senior registrar, in consultation always with the midwife in charge, decides when to terminate labour and also chooses the method of delivery except in the case of a caesarean section

\footnotetext{
${ }^{11}$ O Reino Unido é um Estado soberano, composto por Inglaterra, Irlanda do Norte, Escócia e País de Gales. O texto de Bachman (2018) apresenta o cenário do Reino Unido, cujo contexto inclui a Inglaterra.

12 No original: "the heart of many communities".

${ }^{13}$ No original: "While today most births in the UK take place in hospitals rather than at home, midwives are practitioners in their own right, tending to the needs of mothers and babies throughout pregnancy, delivery and the post-partum period for around a month. Whether at home, in a hospital or a midwife unit, they are leading health professionals and attend the majority of births."
} 
that must be referred to the consultant'. (DOWNE; DYKES, 2009, p. 75, grifo meu).

A função de determinar o fim do parto é dada a um médico, que "sempre consultando a parteira responsável, decide quando terminar o parto e escolhe o método utilizado, exceto no caso de uma cesárea, quando é necessária a presença de um obstetra". (DOWNE; DYKES, 2009, p. 75, tradução minha, grifo meu).

Nesse cenário, no trecho original, observamos a presença de três profissionais que podem atuar no momento do parto: a midwife, um senior registrar e um consultant. O médico que tem a responsabilidade de decidir se a gestante em questão necessita de um procedimento de cesárea é o consultant, que numa hierarquia seria mais especializado do que o senior registrar, que é o médico que faz o acompanhamento do parto natural. Na tradução feita pela autora do artigo foi utilizado o cenário de que consultant seria um obstetra, enquanto o senior registrar seria uma espécie de clínico geral, que faz a assistência do parto.

Esse cenário é um pouco diferente do que podemos observar no Brasil, onde é obrigatória a presença de um especialista obstétrico, seja ele um enfermeiro ou uma enfermeira, ou um obstetra ou uma obstetriz. De acordo com o Ministério da Saúde (BRASIL, 2016, p. 29), a "assistência ao parto e nascimento de baixo risco que se mantenha dentro dos limites da normalidade pode ser realizada tanto por médico obstetra quanto por enfermeira obstétrica e obstetriz". $\mathrm{Ou}$ seja, diferentemente do cenário retratado na Inglaterra, no Brasil o responsável pelo parto, seja ele natural ou de cesárea, indispensavelmente deve ser um especialista da área de obstetrícia.

Tendo em mente esses dois contextos e as diferenças em alguns traços contidos nos termos, podemos trazer à luz um conceito apresentado por Aixelá (1996). De acordo com ele, os itens culturalmente marcados são esse tipo de componentes estritamente culturais, em oposição àqueles que são estritamente linguísticos ou pragmáticos.

Na perspectiva do autor, “a maior dificuldade na definição está, é claro, no fato de que, numa língua, tudo é culturalmente produzido, começando pela 
própria língua” (AIXELÁ, 1996, p. 57, tradução minha) ${ }^{14}$. Portanto, é de suma importância que, em algum momento, essas distinções sejam marcadas para o leitor do texto, explicando de que forma os cenários se diferem e qual é a relevância dessas diferenças para o texto traduzido.

As distinções mencionadas anteriormente são importantes para ilustrar que as diferenças culturais têm influência não somente nas acepções em relação aos termos 'midwife', 'parteira' e 'obstetra', mas também em relação à organização na estrutura da área de obstetrícia. Temmerman (2004) afirma que compreender um conceito seria o mesmo que classificar modelos cognitivos, de forma que consigamos entender a sua posição numa classificação lógica. Portanto, ao fazer esse levantamento da forma como os dois países concebem esses termos e a forma pela qual esses termos evoluíram diacronicamente, nos ajuda a compreender melhor a significação que o termo possui no seu contexto de criação - e, nesse caso, também no de tradução.

\section{Considerações finais}

A partir dessa contextualização feita dos cenários dos dois países de circulação dos textos, podemos chegar a algumas conclusões. Fazer a escolha dos termos equivalentes no processo de tradução pode ser um trabalho de pesquisa muito grande, como podemos observar, e o resultado nem sempre vai ser satisfatório. Na perspectiva da Teoria Sociocognitiva da Terminologia de Temmerman (2004), de acordo com Maciel (2007, on-line), “o termo não existe a priori denominando um conceito pré-existente no mundo real, mas se constitui em um processo de conceitualização e categorização sociocultural”. Ou seja, o termo é construído conforme o contexto da comunicação especializada.

Dentro de cada um dos contextos, o termo funciona de uma forma, e estabelece relações diferentes. Midwifery é uma profissão regulamentada, onde

${ }^{14}$ No original: "The main difficulty with the definition lies, of course, in the fact that in a language
everything is culturally produced, beginning with language itself." 
as profissionais passam por um treinamento para poderem atuar como tais. Já a função de parteira, no Brasil, não foi regulamentada, e as mulheres que desempenhavam essa profissão possuíam apenas experiência de atuação. A obstetrícia já é um campo de atuação de médicos ou enfermeiros, que possuam uma graduação e especialização na área.

No caso da tradução desse texto, como estávamos trabalhando para e com uma profissional da área, utilizamos os termos que a professora da área de Enfermagem nos indicou como mais adequados no contexto brasileiro. Entretanto, com essa contextualização podemos observar que a escolha de traduzir 'midwifery' por 'obstetrícia' não seria a mais adequada. Porém, tampouco seria adequado utilizar o termo 'parteria', pois a utilização dele remeteria àquela prática antiga ao invés de remeter a uma prática contemporânea. Talvez, futuramente, a partir do movimento que está ocorrendo de humanização do parto no Brasil - que está sendo discutido até a nível oficial no Senado -, a parteira ou até mesmo a doula acabe se tornando parte essencial dos partos humanizados, se tornando uma contribuinte oficial e regulamentada pelo Ministério da Saúde do Brasil. Quando e se este esse for o caso, poderemos dizer que existirá um equivalente para o termo 'midwife'.

A dificuldade de encontrar equivalentes é um problema recorrente na tradução, por ser um movimento que tem como objetivo trazer um texto produzido num cenário cultural para outro cenário cultural, muitas vezes completamente distante daquele original, como é o caso que tratamos aqui. $\mathrm{O}$ Brasil se situa numa distância da Inglaterra que não é apenas geográfica, mas também cultural. O conceito de itens culturalmente marcados de Aixelá (1996) se mostra essencial para enfatizar a importância de sempre ficar atento a estes termos, sempre se preocupando em entregar ao leitor a melhor apresentação possível daquilo que constava no texto original.

Por fim, acreditamos que esse tipo de contextualização seria importante de ser exposta de alguma forma ao leitor da tradução. Talvez introduzi-la como um prefácio na publicação de textos traduzidos que apresentem esses itens culturalmente marcados seria o ideal. 
Por fim, seria interessante, mostrar as distinções no comportamento dos termos, baseando-se nos princípios da Terminologia Sociocognitiva. Aqui neste trabalho foram abordados principalmente os princípios que tratam da diacronia e das estruturas das categorias, que foram os mais relevantes para o tema em questão. 


\section{Referências}

ACKER, Justina Inês Brunetto Verruck et al. As parteiras e o cuidado com o nascimento. Revista brasileira de enfermagem, Brasília, v. 59, n. 5, p. 647-651, out. 2006.

AGUIAR, Janaina Marques; D'OLIVEIRA, Ana Flávia Pires Lucas;

SCHRAIBER, Lilia Blima. Violência institucional, autoridade médica e poder nas maternidades sob a ótica dos profissionais de saúde. Cadernos de Saúde Pública, Rio de Janeiro, v. 29, n. 11, p. 2287-2296, nov. 2013.

AIXELÁ, Javier Franco. Culture-specific Items in Translation. In ALVAREZ, Roman; VIDAL, María del Carmen-Africa. (eds.). Translation, Power, Subversion. Philadelphia: Multilingual matters, 1996, p. 52-78.

BACHMAN, Lorelei. Midwifery in the UK: From Florence Nightingale to Call the Midwife. Anglotopia: [n. i.], 2018. Disponível em:

https://www.anglotopia.net/british-entertainment/brit-tv/midwifery-ukflorence-nightingale-call-midwife/. Acesso em: $26 \mathrm{dez} .2018$.

BERGHAHN BOOKS. Childbirth, Midwifery and Concepts of Time. New York; Oxford, 2020.

BRASIL. Ministério da Saúde. Diretriz Nacional de Assistência ao Parto Normal. Brasília, 2016.

BRASIL. Ministério da Saúde. Parto e nascimento domiciliar assistidos por parteiras tradicionais. Brasília, 2010.

BRASIL. Ministério da Saúde. Pela primeira vez número de cesarianas não cresce no país. Brasília, 2017. Disponível em:

http://portalms.saude.gov.br/noticias/agencia-saude/27782-pela-primeira-veznumero-de-cesarianas-nao-cresce-no-pais. Acesso em: 23 dez. 2018.

CARVALHO, Yuli Souza. "Contando o tempo na gravidez e no parto": tradução comentada de um texto técnico. 2018. Trabalho de Conclusão de Curso (Bacharelado em Letras) - Instituto de Letras, Universidade Federal do Rio Grande do Sul, Porto Alegre, 2018.

DOWNE, Soo; DYKES, Fiona. Counting Time in Pregnancy and Labour. In: MCCOURT, Christine (Org.). Childbirth, Midwifery and Concepts of Time. Oxford: Berghahn Books, 2009. p. 61-83.

GUEDES, Aline. Especialistas apontam epidemia de cesarianas no Brasil. Senado Notícias: Brasília, 2018. 
INTERNATIONAL CONFEDERATION OF MIDWIVES. ICM International Definition of the Midwife. Den Haag, 2017.

KRIEGER, Maria da Graça; FINATTO, Maria José B. Introdução à Terminologia: teoria e prática. São Paulo: Contexto, 2004.

MACIEL, Anna Maria Becker. Pressupostos sociocognitivos na descrição de terminologias e na produção de obras terminográficas. In: Encontro Intermediário do GT de Lexicologia, Lexicografia e Terminologia da ANPOLL, 6., 2007, Porto Alegre, RS. Resumo Expandido. Porto Alegre: UFRGS, 2007.

MCCOURT, Christine. Childbirth, Midwifery and Concepts of Time. Oxford: Berghahn Books, 2009. p. 61-83.

NATIONAL CHILDBIRTH TRUST. Maternity Statistics - England. 2015.

Disponível em: https://www.nct.org.uk/aboutus/professional/research/maternity-statistics/maternity-statistics-england. Acesso em: 26 dez. 2018.

ODOSHINA, Maiumy Huelida Gomes. O Parto na TV: um estudo a partir de um programa de jornalismo utilitário sobre saúde. 2017. Dissertação (Mestrado em Saúde Coletiva) - Centro de Ciências da Saúde, Universidade Federal do Espírito Santo, Vitória, 2017.

O RENASCIMENTO do parto. Direção: Eduardo Chauvet. Produção: Érica de Paula. Roteiro: Érica de Paula. Brasília: Master Brasil e Ritmo Filmes, 2013. Netflix (90 min).

O RENASCIMENTO do parto 2. Direção: Eduardo Chauvet. Distribuição: Vitrine Filmes. Brasília: Master Brasil e Ritmo Filmes, 2018. Netflix (91 min).

O RENASCIMENTO do parto 3. Direção: Eduardo Chauvet. Produção: Eduardo Chauvet. Roteiro: Eduardo Chauvet. Brasília: Master Brasil e Ritmo Filmes, 2018b. Netflix (72 min).

PEREIRA, Amanda Henrique; NADIN, Odair Luiz. Análise da variação terminológica denominativa em textos jurídicos: o caso do termo petição inicial. TradTerm, São Paulo, v.34, p. 121-142, dez. 2019.

TEMMERMAN, Rita. Teoria Sociocognitiva da Terminologia. Tradução de Natacha Enzweiler e Luzia Araújo. Revisão de Talia Bugel. Cadernos de Tradução, Porto Alegre, n. 17, p. 31-50, dez. 2004.

Artigo recebido em 15 de maio de 2020 e aceito em 25 de julho de 2020. 